\title{
Análise comparativa sobre a política de mudanças climáticas nos estados brasileiros da Amazônia Oriental
}

\section{Luana Lopes Costa $^{1}$, Carla Renata de Oliveira Carneiro ${ }^{2}$ e Altem Nascimento Pontes ${ }^{3}$}

\begin{abstract}
${ }^{1}$ Universidade do Estado do Pará. Curso de Graduação em Engenharia Ambiental e Sanitária. Travessa Enéas Pinheiro, 2626. Marco. Belém-PA, Brasil (66095-100). E-mail: luana.costa29@outlook.com.

${ }^{2}$ Universidade do Estado do Pará. Programa de Pós-Graduação em Ciências Ambientais. Travessa Enéas Pinheiro, 2626. Marco. Belém-PA, Brasil (66095-100). ${ }^{3}$ Universidade Federal do Pará. Centro de Ciências Exatas e Naturais. Departamento de Física. Laboratório de Física Pesquisa, Sala 17. Rua Augusto Corrêa, 01. Guamá. Belém-PA, Brasil (CEP 66075-110).
\end{abstract}

\begin{abstract}
Resumo. Atividades antrópicas em busca de recursos naturais para exploração ocasionam alterações climáticas trazendo a necessidade de políticas estaduais que as regulamentem sempre em conformidade com a política nacional e levando em consideração as peculiaridades de cada região. 0 objetivo do trabalho foi analisar comparativamente as políticas de mudanças climáticas nos estados da Amazônia Oriental, pois a região possui grande importância climática e ambiental no território nacional. Para isso realizou-se um estudo das políticas estaduais que tratam sobre mudanças climáticas, suas dinâmicas, compromissos e instrumentos. A análise dos dados foi qualitativa, pautada na comparação das políticas vigentes dos estados, pontuando sua aplicabilidade e efetividade diante do cenário atual levantado através das pesquisas bibliográficas e documentais realizadas. Após o estudo, observou-se que apenas três estados da região estudada (Mato Grosso, Pará e Tocantins) possuem políticas em conformidade com o estabelecido pelo Plano Nacional de Mudanças Climáticas enquanto o Maranhão apresenta o decreto que estabelece o Fórum sobre Mudanças Climáticas e Amapá mostra um retrocesso em relação aos outros estados. Portanto, a Amazônia deve participar de forma urgente na agenda de estudos de alterações climáticas dado que os impactos causados atingem pontualmente as regiões amazônicas refletindo em todos.
\end{abstract}

Palavras-chave: Sustentabilidade ambiental; Legislação ambiental; Impactos ambientais.

Abstract. Comparative analysis on climate change policy in Brazilian states of the Eastern Amazon. Human activities in search of natural resources for exploration cause climate change
Recebido

$08 / 08 / 2020$

Aceito

$06 / 12 / 2020$

Disponível on line

$07 / 12 / 2020$

Publicado

31/12/2020

Acesso aberto

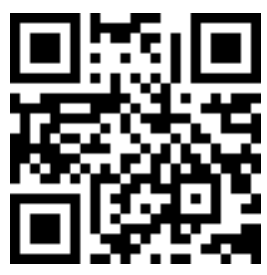

ORCID

(1) 0000-0002-7824-6989

Luana Lopes Costa

D) 0000-0003-4147-2605

Carla Renata de

Oliveira Carneiro ISSN 2359-1412/RBGAS-2020-0123/2020/7/17/30/1499 
bringing the need for state policies that always regulate them in accordance with national policy and taking into account the peculiarities of each region. The objective of the work was to comparatively analyze the climate change policies in the states of the Eastern Amazon, as the region has great climatic and environmental importance in the national territory. To this end, a study of state policies dealing with climate change, its dynamics, commitments and instruments was carried out. The analysis of the data was qualitative, based on the comparison of the current policies of the states, punctuating its applicability and effectiveness in view of the current scenario raised through the bibliographical and documentary researches carried out. After the study, it was observed that only three states in the region studied (Mato Grosso, Pará, and Tocantins) have policies in accordance with the established by the National Plan for Climate Change while Maranhão presents the decree establishing the Forum on Climate Change and Amapá shows a setback compared to other states. Therefore, the Amazon must urgently participate in the climate change study agenda, given that the impacts caused punctually affect the Amazon regions, reflecting everyone.

Keywords: Environmental sustainability; Environmental legislation; Environmental impacts.
(D) 0000-0002-9001-4603

Altem Nascimento

Pontes

\section{Introdução}

É de conhecimento geral a necessidade de estudos que abordem questões concernentes às condições climáticas, por ser um dos principais indicadores de alterações no meio ambiente. Segundo Toledo (2018), as atividades antrópicas degradaram cerca de $75 \%$ da superfície terrestre ocasionando assim a extinção de espécies, intensificando o grau de mudanças climáticas e prejudicando o bem-estar da comunidade mundial. A partir da segunda metade do século XX, além do aumento de temperatura, tem se destacado a elevação do nível do mar, acidificação e degelo de oceanos, com grandes impactos de cunho socioeconômico, razão pela qual exige-se atenção para os possíveis desdobramentos oriundos deste problema (Berlato e Cordeiro, 2018).

Nos anos 1990 impulsionou-se as iniciativas a fim de minimizar os avanços das mudanças climáticas no mundo, destacando-se o primeiro informe lançado pela Organização das Nações Unidas (ONU) em 1990, e, posteriormente, em 1995, quando as maiores potências mundiais iniciaram negociações para fortalecer a resposta global às mudanças climáticas (ONU, 2020). Dois anos depois, as nações entraram em acordo para a adoção do Protocolo de Quioto criando diretrizes para que os países mais poluentes estabelecessem metas para diminuir a emissão de poluentes, estabelecendo assim os primeiros, porém mais importantes, passos para regulamentar esse grau de emissão (Abreu et al., 2020).

0 aquecimento global, o derretimento das calotas polares e geleiras que levam ao aumento do nível dos oceanos, distúrbios no ciclo da água e mudanças na função e composição de ecossistemas, são algumas das várias consequências que as mudanças climáticas provocam em escala global (FAO, 2020). Ademais, nos últimos 50 anos, na Península Antártica, tem-se registrado aumento de $3{ }^{\circ} \mathrm{C}$ na temperatura do ar e $1{ }^{\circ} \mathrm{C}$ na água, sendo tais elevações sido resultado direto das atividades do homem e seu 
descontrolado grau de emissões de $\mathrm{CO}_{2}$ na atmosfera, impactando no ar, mar e organismos vivos existentes nos ecossistemas (Suda et al., 2019).

O Brasil, acompanhando outros países, também está inserido neste cenário de preocupação com a sustentabilidade e o nível de emissão de gases, portanto, neste sentido a Lei no 12.187/2009 instituiu a Política Nacional sobre Mudança do Clima, estabelecendo diretrizes para o desenvolvimento de ações que controlem a emissão de gases do efeito estufa, assim como a criação de exigências internas para enfrentar os impactos das mudanças climáticas no território nacional (Brasil, 2009; Wedy, 2016). Ressalte-se que o mesmo instrumento legal, em seu art. 3oㅡㄹ inciso $\mathrm{V}$, preconiza que as ações de âmbito nacional devem integrar a participação estadual e municipal, além de entidades públicas e privadas (Brasil, 2009).

De acordo Silva e França (2018), as mudanças climáticas são causadas por eventos de origem natural como o ciclo do Sol e a variação orbital, porém, para o Painel Intergovernamental sobre Mudanças Climáticas, as mudanças climáticas atuais são decorrentes de atividades antrópicas, sendo a emissão de gases do efeito estufa e o desmatamento os principais causadores de um aumento de $1{ }^{\circ} \mathrm{C}$ da temperatura global comparada à temperatura global da era pré-industrial (IPCC, 2018). Andrade et al. (2018) complementam, afirmando que a nível regional o desmatamento é considerado o maior gerador de mudanças causando assim variações climáticas nos ecossistemas e elevando a vulnerabilidade da extinção de espécies.

o Brasil detém $12 \%$ da água doce mundial, deste percentual $70 \%$ encontra-se na região amazônica o que leva a grandes responsabilidades no território brasileiro, pois, impactos de degradação podem ocasionar efeitos negativos na emissão de gases de efeito estufa para a atmosfera, levando a impactos climáticos a nível global (Resende et al., 2020; Manzatto et al., 2019). A Amazônia é considerada uma das maiores e mais importantes regiões do mundo e sua existência estabelece um equilíbrio ambiental a nível global, alterações de origens antrópicas como transformações em sistemas agrícolas e/ou pastagens implicam na distribuição de carbono da biosfera para atmosfera interferindo no aquecimento global (Nobre et al., 2007).

A poluição e o aquecimento global resultantes das atividades antrópicas levou a necessidade de elaboração de mecanismos que atuam em conflitos sociais e ambientais, garantindo assim direito aos cidadãos, em decorrência disto, tem-se a implementação de políticas e instrumentos de gestão urbana que garantem o bem-estar, além de focar nos aspectos locais de cada região, garantindo o crescimento sustentável e a utilização de inovações menos poluidoras (Castro et al., 2017). A adoção de políticas voltadas para o crescimento sustentável é fundamental, para isso, de acordo com o Ministério do Meio Ambiente, é através de estratégias respaldadas legalmente, e com a cooperação técnica e científica com instituições relacionadas ao tema, que o país irá alcançar os compromissos de redução de emissão de gases (MMA, 2020a).

De acordo com o IPCC (2018), a adaptação feita pelos países mais poluidores para se alcançar o nível de aceitação de emissão de gases do efeito estufa, estabelecido pelo Acordo de Paris, não está sendo suficiente. Isso porque as mudanças climáticas estão relacionadas ao desenvolvimento sustentável e podem gerar impactos em médio e longo prazos em aspectos econômicos, sociais e ambientais, principalmente em nível regional. Cabe à legislação estadual garantir e estabelecer diretrizes para retardar essas emissões. Levando em consideração essas afirmações, o objetivo do presente trabalho foi analisar comparativamente a política de mudanças climáticas nos estados da Amazônia Oriental, já que esta região tem grande importância climática e ambiental no território nacional.

Rev. Bras. Gest. Amb. Sustent., 2020, vol. 7, n. 17, p. 1519-1532. 


\section{Material e métodos}

\section{Área de estudo}

0 presente trabalho realizou um estudo das políticas estaduais que tratam sobre mudanças climáticas, suas dinâmicas, compromissos e instrumentos dos estados que compõem a região denominada Amazônia Oriental, com ênfase no viés da similitude entre tais políticas.

A Amazônia Legal é um conceito político que visou o desenvolvimento dos estados que originalmente possuíam desafios sociais, políticos e econômicos, também estabeleceu divisões em Amazônia Ocidental e Amazônia Oriental. Sendo a primeira composta por Amazônia, Roraima, Rondônia e Acre com uma área de 25,7\% do território brasileiro e, o segundo, por exclusão formados pelos estados descritos na Tabela 1 (SUDAM, 2020).

Tabela 1. Estados que compõe a Amazônia Oriental.

\begin{tabular}{|l|c|c|}
\hline Estados & Área territorial $\mathbf{( k m}^{\mathbf{2}} \mathbf{)}$ & Habitantes* \\
\hline Pará & $1.245 .870,798$ & 8.602 .865 \\
\hline Maranhão & $329.642,182$ & 7.075 .181 \\
\hline Amapá & $142.470,762$ & 845.731 \\
\hline Tocantis & $277.466,763$ & 1.572 .866 \\
\hline Mato Grosso & $903.207,019$ & 3.484 .466 \\
\hline
\end{tabular}

*População estimada para o ano de 2019. Fonte: IBGE (2020).

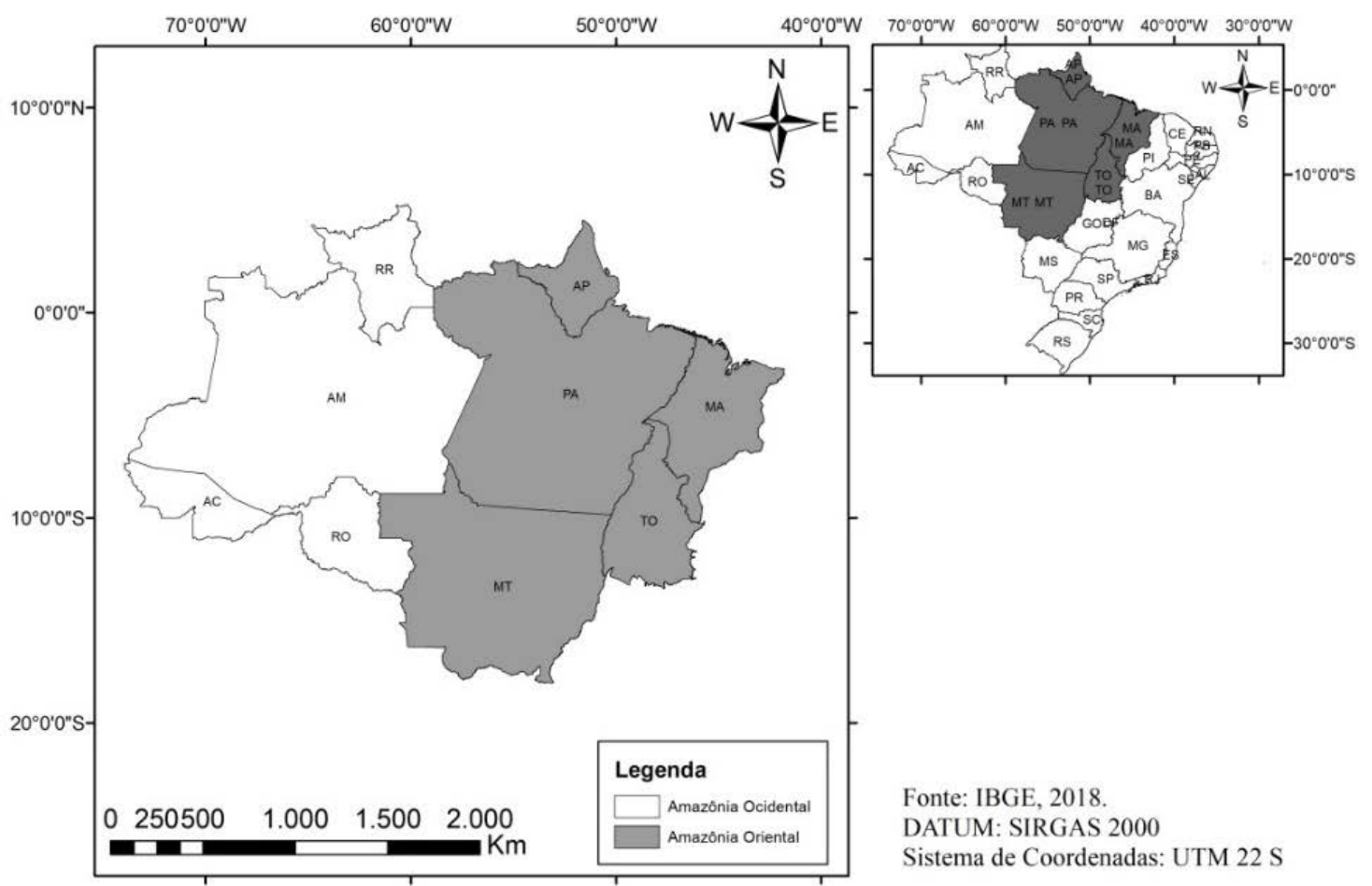

Figura 1. Mapa da Amazônia Legal. 
Esta divisão vai além de limites geográficos, incorporando parte do bioma Cerrado e parte do Pantanal, portanto as características de solo e clima são distintas em cada região, sendo evidenciada tal diferença conforme Figura 1, onde mostra a localização dos respectivos estados.

\section{Caracterização da pesquisa}

Quanto à abordagem, a pesquisa foi qualitativa permitindo a compreensão e interpretação dos dados obtidos; de natureza básica, possibilitando a transmissão e debate do conhecimento adquirido. Quanto ao objetivo, a pesquisa tem cunho exploratório, pois se trata da investigação de um problema não totalmente definido utilizando a temática de comparação de legislação sobre mudanças climáticas. No que tange aos procedimentos, a pesquisa foi bibliográfica e documental.

A coleta de dados ocorreu por meio de estudo e interpretação das legislações de cada estado componente da Amazônia Oriental, focando no viés dos compromissos e instrumentos de cada política visando a diminuição dos impactos que as mudanças climáticas podem causar, além de encontrar afinidades que aproximam tais políticas.

A análise dos dados foi qualitativa, pautada na comparação das políticas vigentes dos estados, pontuando sua aplicabilidade e efetividade diante do cenário atual levantado através das pesquisas bibliográficas e documentais realizadas.

\section{Resultados e discussão}

Com base nas análises realizadas, dos cinco estados componentes da Amazônia Oriental, somente os Estados do Pará, Tocantins e Mato Grosso possuem legislação vigente sobre mudanças climáticas, sendo elas, respectivamente, a Lei no 9.048/2020 (Pará, 2020), a Lei no 1.917/2008 (Tocantins, 2008), e a Lei Complementar no 582/2017 (Mato Grosso, 2017). O Estado do Amapá possui um documento legislativo denominado Minuta Preliminar que define as diretrizes do clima, porém sem aprovação, logo sem força de lei (Amapá, 2009), enquanto que o Maranhão tem realizado discussões preliminares, documentado em um Fórum sobre o Clima, contudo, sem política vigente.

Vale destacar a importância do Plano Nacional de Mudanças Climáticas nesse cenário, pois as políticas estaduais possuem como base as diretrizes estabelecidas no plano nacional, ou seja, tanto em âmbito nacional quanto estadual, buscam promover a redução da emissão de gases poluentes, além de estabelecer regulamentos e limites para a atual emissão.

Diante de inúmeras diretrizes e disposições legais nas políticas, a presente pesquisa buscou enfoque nos Instrumentos e Compromissos que os estados apresentam como forma de minimizar e trabalhar os impactos advindos das mudanças climáticas. Assim, é possível desdobrar as similitudes e divergências entre as políticas atuais.

\section{Dos instrumentos}

Os instrumentos nas políticas públicas possuem a finalidade de melhorar a gestão governamental além de ajudar na execução das mesmas. Ollaik e Medeiros (2011) definem instrumento governamental como um "[...] método identificável por meio do qual a ação coletiva é estruturada para lidar com um problema público [...]", além de ser de grande importância ao analisar qual o papel da gestão governamental e da sociedade como um todo. Assim, a Tabela 2 apresenta as similitudes e as divergências entre as políticas estaduais dos Estados do Pará, Mato Grosso e Tocantins no que tange aos seus instrumentos. 
Tabela 2. Comparativo sobre os instrumentos dispostos na Política Estadual de Mudanças Climáticas dos estados do Pará, Mato Grosso e Tocantins.

\begin{tabular}{|c|c|c|}
\hline \multicolumn{3}{|c|}{ Instrumentos } \\
\hline Pará (Lei no 9.048/2020) & $\begin{array}{c}\text { Mato Grosso (Lei no } \\
582 / 2017 \text { ) }\end{array}$ & $\begin{array}{c}\text { Tocantins (Lei } \mathrm{n}^{\circ} \\
1.917 / 2008)\end{array}$ \\
\hline $\begin{array}{l}\text { Art. 22. Compõem a Política } \\
\text { Estadual sobre Mudanças } \\
\text { Climáticas do Pará: } \\
\text { I - gestão pública sustentável; } \\
\text { II - instrumentos de educação, } \\
\text { pesquisa e inovação; } \\
\text { III - instrumentos de } \\
\text { transparência } \\
\text { comunicação; } \\
\text { IV - instrumentos econômicos, } \\
\text { financeiros e fiscais; e } \\
\text { V - Plano Estadual sobre } \\
\text { Mudanças Climáticas. }\end{array}$ & $\begin{array}{l}\text { Art. 14 São instrumentos da } \\
\text { Política Estadual de Mudanças } \\
\text { Climáticas: } \\
\text { I Plano Estadual de Mudanças } \\
\text { Climáticas; } \\
\text { II instrumento de informação e } \\
\text { gestão; } \\
\text { III instrumentos de comando e } \\
\text { controle; } \\
\text { IV instrumentos econômicos; } \\
\text { V programas e projetos de } \\
\text { mitigação de GEE; } \\
\text { VI licitações sustentáveis; } \\
\text { VII educação, pesquisa, } \\
\text { comunicação e disseminação; } \\
\text { VIII adaptação e defesa civil; } \\
\text { IX Fundo Estadual de } \\
\text { Mudanças Climáticas. }\end{array}$ & $\begin{array}{l}\text { CAPÍTULO V - Instrumentos } \\
\text { fiscais e financeiros. } \\
\text { Seção I - Das Linhas de Crédito } \\
\text { e Financiamento } \\
\text { Seção II - Dos Incentivos } \\
\text { Fiscais }\end{array}$ \\
\hline
\end{tabular}

Da criação do Plano Estadual sobre mudanças climáticas. Diante do Tabela 2, inicialmente, cabe ressaltar que tanto o estado do Pará quanto Mato Grosso estão em conformidade com a Política Nacional no que tange à criação do Plano Estadual sobre Mudanças Climáticas em suas políticas. 0 referido plano estadual, presente em ambas as políticas, por ser dotado da característica de instrumento, busca viabilizar a implantação da política estadual como um todo e neste sentido o Estado do Pará estabelece requisitos mínimos dispostos no art. 32 e seus incisos para a criação sistematizada do Plano, como diagnóstico atual dos estoques de carbono, com atualização periódica, estratégia de transição para economia de baixo carbono e planos setoriais com regulamento próprio (Pará, 2020).

Acompanhando o estado do norte, o estado do Mato Grosso em seu art. 15 também coaduna em estabelecer critérios mínimos para que o referido plano estadual seja executado, como diagnósticos com mapeamento das vulnerabilidades e suscetibilidades esperadas, bem como a criação de planos setoriais para medidas de mitigação e adaptação considerando vários aspectos, com cronograma e recursos para sua implementação (Mato Grosso, 2017).

Enquanto isso a política do estado de Tocantins não explicita na legislação um Plano de mudanças climáticas acompanhando os demais estados citados, em ordem disto enfatiza apenas instrumentos de cunho financeiro e fiscal, fazendo uso de estratégias de financiamento de atividades e projetos que garantam o desenvolvimento sustentável, valendo-se inclusive de recursos nacionais e internacionais para financiamento dos projetos, conforme art. 7ํ, caput da legislação (Tocantins, 2008).

Na prática, o Estado do Mato Grosso realiza anualmente o Fórum de Mudanças Climáticas onde apresenta inventários e informações técnicas fornecidas pela sociedade civil e colaboradores, este levantamento de dados é necessário para se estabelecer programas para redução de gases. Desde 2017, o estado adere ao programa REM-MT apresentado na Conferencia Rio+20, em 2012, premiando pioneiros em proteção florestal 
e mitigação de efeitos climáticos, pois o Estado apresentou uma redução de $90 \%$ do desmatamento entre 2004-2014 (FUNBIO, 2020). O Fórum Mato-grossense de 2019 apresentou atualização dos dados deste programa que recebe incentivos de projetos provenientes da Alemanha e Reino Unido, cerca de 60 milhões (Prata, 2019).

Já o estado do Pará por possuir uma legislação recente, ainda não possui informações e outros subsídios para estabelecer um plano estadual, estando dentro do prazo legal de três anos, a partir da publicação de sua Lei para aprovação de um efetivo plano estadual, conforme o art. 32 (Pará, 2020).

Dos instrumentos de finalidade econômica. Conforme já exposto, o estado do Tocantins possui ênfase em instrumentos de cunho financeiro e fiscal, com incentivo às atividades e projetos que atendam a legislação nacional e internacional gerando benefícios a médio e longo prazos ao meio ambiente, garantindo um desenvolvimento sustentável e consequentemente qualidade de vida. E nesta continuidade, Mato Grosso e Pará, também possuem instrumentos ligados a este aspecto, fazendo uso do mesmo objetivo para 0 incentivo de atividades que gerem a prevenção, mitigação e adaptação, relacionadas às mudanças climáticas conforme prelecionado no art. 19 e art. 29 de cada política, respectivamente (Mato Grosso, 2017; Pará, 2020).

Em uma esfera mais abrangente, a Política Nacional estabelece que medidas fiscais e tributárias, financeiras e econômicas devem ser aplicadas em âmbito nacional, desde que em legislação específica, além disso, deve-se estabelecer linhas de crédito e de financiamento estimuladas por agentes financeiros em favor das questões ambientais sobre a emissão de gases e mudanças climáticas (Tocantins, 2009).

Os Estados do Mato Grosso e do Pará seguem todos os instrumentos elencados na Política Nacional, contudo na política do Pará verificam-se algumas peculiaridades quanto aos instrumentos econômicos, como a autorização para o uso de doações por entidades públicas e privadas, nacionais e internacionais, assim como o uso de recursos provenientes de contratos e convênios com entidades públicas federais, estaduais e municipais, linhas de crédito, pagamento por serviços ambientais, selos de certificação, entre outros dispostos no Art. 30 e seus incisos. Ambas as políticas, como meio de coibir a execução de atividades que possam impedir os objetivos, determinam a revogação dos benefícios em caso de irregularidade e descumprimento de qualquer ato disposto nas suas respectivas políticas.

Dos instrumentos de educação e pesquisa. No que tange aos instrumentos de educação e pesquisa vê-se que a política do Pará descreve melhor seus critérios usando a educação e conscientização ambiental como preceitos, conforme art. 26 , da Lei $\mathrm{n}$ o 9.048/2020, além de incentivar a criação de centros de inovação para promoção do desenvolvimento dentro dos padrões aceitáveis ao se tratar de mudanças climáticas (Pará, 2020). E neste sentido, tanto o estado do Mato Grosso quanto o Pará estabelecem que entidades públicas e privadas devem incentivar tais pesquisas a fim de garantir maior envolvimento da sociedade como um todo.

A política nacional preleciona que se deve desenvolver como política linhas de pesquisa por agências de fomento, bem como medidas de divulgação, conscientização e educação, conforme art. 6o, incisos VIII e XIV, da Lei no 12.187/2009 (Brasil, 2009). Contudo, na contramão da Política Nacional, o Estado do Tocantins, não estabelecce uma definição específica como instrumento inerente à educação e pesquisa, o que se vislumbra no decorrer do texto da lei tocantinense é um enfoque no estímulo à educação ambiental como objetivo a ser alcançado e fomentado pelo estado e instituições privadas (Tocantins, 2008).

Para se desenvolver é necessário diversos recursos como materiais, pessoas, recursos financeiros e recursos naturais. 0 consumo exacerbado leva a mudanças 
climáticas e impactos de devastação global, por isso a relação entre pessoas e recursos naturais devem ser harmônica (Rodrigues et al., 2017). Fernandes Silva et al. (2016) mostram em seu trabalho a importância da chamada Educação em Mudanças Climáticas que busca uma educação ambiental dando ênfase a fatores climáticos permitindo assim, mudança nos padrões de vida das pessoas garantindo atitudes mais sustentáveis por parte da sociedade além de incentivar a diminuição do consumismo em razão da mitigação de gases poluentes. Razão pela qual imperiosa a necessidade de tal instrumento se fazer presente e efetivo em todas as políticas.

Dos instrumentos de informação e gestão. No que tange aos instrumentos de informação e gestão, também chamados de instrumento de transparência e de comunicação, as políticas do Pará e Mato Grosso são bem equivalentes estabelecendo uma publicação periódica de inventários de emissões antrópicas.

Ao explorar as particularidades presentes em cada política, nota-se que a do Pará determina a criação de um instrumento chamado de Gestão Pública Sustentável que traz o incentivo do consumo sustentável por parte de servidores assim como o emprego de políticas socioambientais, assim, esta sensibilização se faz necessário para criar uma nova cultura de sustentabilidade, além de contribuir para a qualidade ambiental e garantir uma relação equilibrada entre sociedade e ambiente, pois gera consequência direta na conservação dos ecossistemas (MMA, 2020b).

Enquanto isso, a política do Mato Grosso possui instrumentos de comando e controle que estão ausentes em outras políticas, definindo que os licenciamentos ambientais devem incorporar dados de emissões de gases em atividades poluidoras e potencialmente poluidoras. Além disso, existe outro instrumento de Programas e Projetos de Mitigação de Emissão de Gases Efeito Estufa onde estabelece que atividades e projetos de redução e controle, mitigação e compensação de gases devem ser implementados pelo Estado de modo que seja benéfico para toda a sociedade além da criação de incentivos para tais projetos, se assemelhando ao descrito na legislação do Tocantins.

Oliveira e Santos (2015) afirmam que as organizações públicas devem usar compras de serviços e produtos favorecendo a sustentabilidade e outros requisitos como custo-benefício, ciclo de vida, além de garantir que a compra gere benefício a longo prazo para todos. Em favor disto, a política possui um instrumento chamado de licitações sustentáveis, ou seja produtos e serviços adquiridos pelo Estado que devem estar de acordo com os critérios de sustentabilidade de modo que o ciclo de vida do produto seja levado em consideração.

Além disso, o Estado do Mato Grosso exige certificação de origem dos materiais adquiridos fora do território e o art. 26 traz uma especificidade em relação à madeira para obras e afins, de modo que as mesmas devem ser originadas a partir do manejo sustentável tanto dentro do estado como fora (Mato Grosso, 2017).

Na legislação mato-grossense existe um instrumento chamado Adaptação e Defesa Civil onde indica criação de órgãos, núcleos e outros meios de ação para atender os objetivos traçados pela política, ou seja, a mitigação e/ou redução dos gases causadores do efeito estufa, sendo cargo do estado mapear áreas e vulnerabilidade. Assim, a Art. 29 destaca a necessidade e responsabilidade do Sistema da Defesa civil na educação da população para conservação de recursos naturais minimizando a poluição e possíveis emissões por parte da comunidade (Mato Grosso, 2017).

Diante dos principais instrumentos elencados, vislumbra-se que a legislação dos estados pesquisados buscam seguir as diretrizes instituídas pela Política Nacional, onde o Estado do Pará e Mato Grosso tendem a organizar seus instrumentos de forma mais fidedigna ao âmbito nacional, já o Estado do Tocantins com enfoque maior em instrumentos fiscais e econômicos, deixa os demais compromissos sobre outras denominações, como objetivos, porém, a obrigatoriedade de se cumprir não fica 
prejudicada, uma vez que a política para ser efetiva deve caminhar de forma conjunta no cumprimento do que dispõe todos os artigos.

\section{Dos compromissos}

A utilização de compromissos em políticas exige o comprometimento do poder público para estabelecer e concretizar as metas criadas. Quando se trata de compromissos dispostos nas políticas públicas dos três estados (PA, MT e TO) é possível observar que são organizados na forma de metas, como mostra a Tabela 3.

Tabela 3. Comparativo sobre os compromissos dispostos na Política Estadual de Mudanças Climáticas dos Estados do Pará, Mato Grosso e Tocantins.

\begin{tabular}{|c|c|c|}
\hline \multicolumn{3}{|c|}{ Compromissos } \\
\hline Pará (Lei no 9.048/2020) & $\begin{array}{c}\text { Mato Grosso (Lei no } \\
582 / 2017)\end{array}$ & $\begin{array}{c}\text { Tocantins (Lei no } \\
1.917 / 2008)\end{array}$ \\
\hline $\begin{array}{l}\text { Art. 33. Para alcançar os } \\
\text { objetivos desta Política, o } \\
\text { Estado adotará ações de } \\
\text { redução de emissões associadas } \\
\text { às fontes antrópicas de gases de } \\
\text { efeito estufa, por meio do } \\
\text { estabelecimento de metas a } \\
\text { serem definidas } \\
\text { regulamento próprio. } \\
\S \text { o o prazo de revisão das } \\
\text { metas deverá ser definido em } \\
\text { regulamento previsto no caput } \\
\text { deste artigo. } \\
\S \text { 2o As metas deverão ser } \\
\text { definidas com base no } \\
\text { inventário de gases de efeito } \\
\text { estufa do Estado e, na sua } \\
\text { ausência, nos relatórios do } \\
\text { Sistema de Estimativa de } \\
\text { Emissões de Gases de Efeito } \\
\text { Estufa - SEEG. }\end{array}$ & $\begin{array}{l}\text { Art. 38. Para alcançar os } \\
\text { objetivos desta Política, o } \\
\text { Estado adotará a assunção de } \\
\text { ações de mitigação, com vistas a } \\
\text { reduzir as emissões associadas } \\
\text { às fontes antrópicas de gases de } \\
\text { efeito estufa GEE, por meio do } \\
\text { estabelecimento de metas a } \\
\text { serem definidas em } \\
\text { regulamento próprio, com base } \\
\text { nos inventários setoriais de } \\
\text { emissões de gases de efeito } \\
\text { estufa do Estado. } \\
\text { § 1o As metas deverão ser } \\
\text { definidas em até } 6 \text { (seis) meses } \\
\text { após a publicação do inventário } \\
\text { de emissões de GEE do Estado. } \\
\text { § 2o A revisão das metas deverá } \\
\text { acompanhar a revisão do Plano } \\
\text { Estadual de Mudanças } \\
\text { Climáticas. } \\
\text { § 3o As ações de mitigação e } \\
\text { adaptação definidas para } \\
\text { cumprimento das metas } \\
\text { deverão ser mensuráveis, } \\
\text { reportáveis e verificáveis. }\end{array}$ & $\begin{array}{l}\text { Art. 1 [...] } \\
\text { Parágrafo único. Para os fins do } \\
\text { disposto nesta Lei, é necessário } \\
\text { considerar: } \\
\text { I - o reconhecimento da } \\
\text { importância da conservação das } \\
\text { florestas, do cerrado e da } \\
\text { biodiversidade diante das } \\
\text { atividades antrópicas que } \\
\text { provocam os efeitos nocivos da } \\
\text { mudança global do clima e os } \\
\text { compromissos fundamentais do } \\
\text { Estado do Tocantins com o } \\
\text { desenvolvimento sustentável } \\
\text { da economia, do meio ambiente, } \\
\text { da tecnologia e da qualidade de } \\
\text { vida das presentes e futuras } \\
\text { gerações; }\end{array}$ \\
\hline
\end{tabular}

Os compromissos são materializados através de ações com vistas a reduzir as emissões de gases e cada política enfatiza a criação de metas para tal cumprimento, que devem ser pautadas a partir de dados contidos em relatórios sobre emissões, com prazo de criação definidos por cada estado.

Os compromissos das políticas do Pará e Mato Grosso estão relacionados à necessidade de garantir melhores condições ambientais a fim de atingir os objetivos propostos por cada política para redução de emissões de gases que consequentemente causam as mudanças climáticas. Para Fernandes Silva et al. (2016) os problemas decorrentes das alterações climáticas requerem esforço contínuo, com ações pautadas na 
conscientização ambiental garantindo assim a saída do estado de inercia social perante as mudanças climáticas já que grande parte da comunidade tem ignorado e/ou não possuem consciência das consequências advindas das transformações climáticas, ou seja, ações voltadas para a dinâmica de mitigação e desenvolvimento sustentável garantem uma mudança de comportamento da coletividade.

As políticas do Pará e Mato Grosso possuem esta definição bem parecida dando ênfase às chamadas ações de mitigação que fornecem benefícios a nível global já que foi definido que a ações desse cunho permitem que a média da temperatura global da atmosfera terrestre se estabilize dentro de algumas décadas (MMA, 2020c). Dessa forma, ambas as políticas baseiam-se em metas a serem definidas e revisadas periodicamente com a inclusão das medidas de mitigação.

Quando se trata de compromissos na política do estado do Tocantins vislumbra-se que não há um capítulo específico definido como nos demais estados, contudo, é de se ressaltar que tem estabelecido no parágrafo único do art. $1^{\circ}$ a importância da conservação de florestas diante das atividades antrópicas (Tocantins, 2008). Trata-se de um artigo relevante, uma vez que corrobora com Ferreira et al. (2017) que afirmam sobre os prejuízos que as ações antrópicas promovidas pela crescente exploração de recursos naturais têm causado para o aumento da temperatura regional e também ainda complementa que a falta de conscientização e a não conservação das florestas nativas podem culminar em alterações de nível global.

Além disso, verifica-se como compromisso da política estadual de mudanças climáticas do Tocantins a busca pelo desenvolvimento sustentável da economia, meio ambiente e da qualidade de vida de gerações atuais e futuras, contudo não se visualiza como nos demais estados a definição de metas ou estratégias de mitigação para redução de gases, através de um documento próprio que possa moniorar e nortear o cumprimento destes compromissos (Tocantins, 2008).

Ao analisar os outros estados que compõem a Amazônia Oriental verifica-se um atraso na definição de políticas sobre mudanças climáticas. 0 Estado do Maranhão possui o Decreto no 22.735/2006, instituindo o Fórum Maranhense de Mudanças Climáticas com o objetivo semelhante ao das políticas de mudanças climáticas dos demais estados além de recolher subsídios para a criação e formulação de novas políticas públicas que poderão ser consolidadas (Maranhão, 2006). 0 Estado do Amapá possui um projeto de Lei da Política Estadual de Mudanças Climáticas estabelecido de 2009 que não foi aprovado (Amapá, 2009), portanto é o único estado da região que não apresenta nenhuma normativa, decreto ou política vigente.

As políticas públicas criadas nos estados não devem se concentrar apenas no repasse de renda e recursos necessários, mas deve criar mecanismos que capacitem a sociedade a trabalhar em conjunto na mitigação dos problemas climáticos, antecipando seus efeitos a fim de reduzir os impactos ocasionados (Queiroz et al., 2016). Além disso, a implementação das políticas apesar de apresentar similaridades, não deve seguir padrões fixos, haja vista as peculiaridades de cada região, distintas realidades territoriais exigem adequação para as questões sociais, institucionais, políticas e de infraestrutura, necessárias para criar estratégias de adaptação às alterações climáticas existentes (Milhorance et al., 2019).

\section{Considerações finais}

Diante do exposto acerca das políticas de mudanças climáticas vigentes nos estados da Amazônia Oriental, área de grande importância para a economia nacional, apenas Mato Grosso, Pará e Tocantins possuem legislações efetivas. Tendo em vista o cenário atual que alterações no clima podem causar no globo, observou-se que as políticas estão em conformidade com o estabelecido pelo Plano Nacional de Mudanças Climáticas. 
Porém, vale ressaltar a necessidade de atualização da política do estado do Tocantins onde se constata a notoriedade dos instrumentos de cunho financeiro, principalmente em relação à busca de financiamento, em contrapartida as políticas dos estados do Mato Grosso e Pará possuem instrumentos de educação, transparência e gestão. Em relação aos compromissos, todas as três políticas estão em conformidade em mitigação de emissão de gases e conservação de florestas nativas a fim de garantir menores impactos advindos da exploração de recursos atingindo os objetivos propostos.

Enquanto isso, o Estado do Maranhão apresenta o Decreto no 22.735/2006 (Maranhão, 2006), que institui o Fórum sobre Mudanças Climáticas, ou seja, um projeto para uma legislação vigente tendo em vista que os estados com políticas estabelecidas possuíam Fóruns para discussão do tema. Em contrapartida, o Estado do Amapá não possui nenhuma política vigente o que mostra um retrocesso da gestão governamental.

Sabe-se que a ausência de um documento legal instituindo políticas que atuem na mitigação dos impactos decorrentes das mudanças climáticas não pode ser razão para a omissão dos estados diante dos problemas abordados. Neste sentido, destaca-se o estado do Pará, que apesar de ter uma política recente, tem registros de ações governamentais estratégicas para mitigação e adaptação climática.

Dentre elas, podem-se citar alguns programas de governo do Pará, como o Plano Estadual de Prevenção, Controle e Alternativas ao Desmatamento do Estado, criado em 2009, com metas de redução do desmatamento, o Programa Municípios Verdes, em 2011, que, com o auxílio da sociedade civil e o Ministério Público Federal, fiscalizava o desmatamento e incentivava a produção rural de forma sustentável. O ICMS Verde, em 2013, como estímulo financeiro, e o Plano Agricultura de Baixo Carbono, em 2012, com o fim de incentivar tecnologias de baixa emissão de carbono (Rocha, 2019).

No Estado do Tocantins pesquisas constataram que há possibilidades de aquecimento do estado em algumas regiões e que tais projeções climáticas demonstram a necessidade de políticas públicas para a redução de emisão de gases advindas da atividade humana, além disso, destacaram-se impactos na disponibilidade hídrica em decorrência das alterações do clima e diminuição de precipitação, exigindo assim maior necessidade de ações mitigadoras (Sousa et al., 2019).

As mudanças climáticas no planeta tendem a inevitavelmente gerar discussões globais, contudo diante da necessidade de soluções não apenas gerais, mas também locais, a Amazônia deve participar de forma urgente nesta agenda de estudos, uma vez que os impactos de alterações climáticas atingem pontualmente as regiões amazônicas refletindo em todos, motivo pelo qual a implementação de ações do estado devem acompanhar o setor privado e as diretrizes internacionais, por ser um problema coletivo e de consequências com dimensões ainda inestimáveis.

\section{Conflito de interesses}

Os autores declaram não haver conflito de interesses.

\section{Referências}

Abreu, A. M.; Sátiro, G.; Litre, G.; Santos, L.; Oliveira, J. E.; Soares, D.; Ávila, K. A interface entre saúde, mudanças climáticas e uso do solo no Brasil: uma análise da evolução da produção científica internacional entre 1990 e 2019. Saúde e Sociedade, v. 29, n. 2, e180866, 2020. https://doi.org/10.1590/s0104-12902020180866

Rev. Bras. Gest. Amb. Sustent., 2020, vol. 7, n. 17, p. 1519-1532. 
Amapá. Projeto de Lei de 15 de setembro de 2009. Institui a Política Estadual sobre Mudanças Climáticas e estabelece outras providências. Disponível em: <https://cetesb.sp.gov.br/proclima/wp-content/uploads/sites/36/2014/08/lei_clima_ap _13set09.pdf>. Acesso em: 15 jun. 2020.

Andrade, B. S.; Singh, C. L.; Santos J. A.; Goncalves, V. V. C.; Siqueira-Souza, F. K.; Freitas, C. E. C. Efeitos das mudanças climáticas sobre as comunidades de peixes na Bacia Amazônica. Revista Ciências da Sociedade, v. 2, n. 4, p. 107-124, 2018. https://doi.org/10.30810/ rcs.v2i 4.905

Berlato, M. A.; Cordeiro, A. P. A. Sinais de mudanças climáticas globais e regionais, projeções para o século XXI e as tendências observadas no Rio Grande do Sul: uma revisão. $\begin{array}{lllll}\text { Agrometeoros, } & \text { v. 25, } & \text { n. 2, } & \text { p. 273-302, 2018. https://doi.org/10.31062/ }\end{array}$ agrom.v25i2.25884

Brasil. Lei no 12.187, de 29 de dezembro de 2009. Institui a Política Nacional sobre Mudança do Clima-PNMC e dá outras providências. Disponível em: <http://www.planalto.gov.br/ccivil_03/_ato2007-2010/2009/lei/L12187.htm>. Acesso em: 7 jun. 2020.

Castro, C. O.; Veneral, D. C.; Sabião, T. J. A mudança climática sustentabilidade e gestão das cidades. Anais Eletrônicos do XVI Congresso Paranaense de Educação Ambiental, Curitiba, p. 1430-1432, 2017. Disponível em: <http://www.epea2017.ufpr.br/>. Acesso em: 15 jun. 2020.

FAO - Food and Agriculture Organization of the United Nations. Climate change. 2020. Disponível em: <http://www.fao.org/climate-change/en/>. Acesso em: 15 de jun. 2020.

Fernandes Silva, C. M. L.; Costa, F. A.; Borba, G. L. A educação em mudanças climáticas: uma abordagem interdisciplinar. HOLOS, v. 4, p.176-188, 2016. https://doi.org/10.15628/ holos.2016.3950

Ferreira, P. S.; Galvíncio J. D.; Gomes, V. P.; Souza, W. M. As perspectivas e divergências sobre o aquecimento antropogênico global. Caderno de Geografia, v. 27, n. 51, p. 728-747, 2017. https://doi.org/10.5752/p.2318-2962.2017v27n51p728

FUNBIO - Fundo Brasileiro para a Biodiversidade. REM Mato Grosso. 2020. Disponível em: <https://www.funbio.org.br/programas_e_projetos/redd-para-pioneiros-mato-grosso/>. Acesso em: 19 jul. 2020.

IBGE - Instituto Brasileiro de Geografia e Estatística. Cidades. 2019. Disponível em: $<$ https://cidades.ibge.gov.br/>. Acesso em: 22 jun. 2020.

IPCC - Intergovernmental Panel on Climate Change. Climate Change 2018. An IPCC special report on the impacts of global warming of $1.5^{\circ} \mathrm{C}$ above pre-industrial levels and related global greenhouse gas emission pathways, in the context of strengthening the global response to the threat of climate change, sustainable development, and efforts to eradicate poverty. Summary for policymakers. Disponível em: <https://www.ipcc.ch/sr15/>. Acesso em: 09 jun. 2020.

Manzatto, C. V.; Assad, E. D.; Pereira, S. E. M.; Loebmann, D. G. S. W.; Spinelli, L.; Vicente, L. E.; Sampaio, F. G.; Sotta, E. D.; Vicente, A. K. Contribuição do plantio direto para a mitigação e a adaptação às mudanças climáticas. AgroANALYSIS, v. 39, n. 12, p. 26-27, 2019.

Maranhão. Decreto no 22.735, de 29 de novembro de 2006. Institui o Fórum Maranhense de Mudanças Climáticas, e dá outras providências. Disponível em: <http://forumempresarialpeloclima.org.br/wp-content/uploads/2012/11/MR_MA_ FORUM.pdf>. Acesso em: 5 jun. 2020. 
Mato Grosso. Lei Complementar no 582, de 13 de janeiro de 2017. Institui a Política Estadual de Mudanças Climáticas. Disponível em: <https://www.normasbrasil.com.br/ norma/lei-complementar-582-2017-mt_335779.html>. Acesso em: 5 jun. 2020.

Milhorance, C.; Mendes, P.; Mesquita, P.; Morimura, M.; Reis, R.; Rodrigues Filho, S.; Bursztyn, M. 0 desafio da integração de políticas públicas para a adaptação às mudanças climáticas no Semiárido brasileiro. Revista Brasileira de Climatologia, v. 24, p. 175-195, 2019. https://doi.org/10.5380/abclima.v24i0.56484

MMA - Ministério do Meio Ambiente. Mitigação da mudança do clima. 2020. Disponível em: $\quad$ <https://www.mma.gov.br/informma/item/229-mitigação-da-mudança-doclima.html>. Acesso em: 14 jul. 2020.

MMA - Ministério do Meio Ambiente. Clima. 2020. Disponível em: <https://www.mma.gov.br/clima.html>. Acesso em: 16 de jun. 2020.

MMA - Ministério do Meio Ambiente. Sensibilização e capacitação dos servidores. 2020. Disponível em: <https://www.mma.gov.br/destaques/item/528-eixos-temáticossensibilização-e-capacitação-dos-servidores.html>. Acesso em: 19 jul. 2020.

Nobre, C. A.; Sampaio, G.; Salazar, L. Mudanças climáticas e Amazônia. Ciência e Cultura, v. 59, n. 3, p. 22-27, 2007.

Oliveira, B. C. S. C. M.; Santos, L. M. L. Compras públicas como política para o desenvolvimento sustentável. Revista de Administração Pública, v. 49, n. 1, p. 189-206, 2015. https://doi.org/10.1590/0034-76121833

Ollaik, L. G.; Medeiros, J. J. Instrumentos governamentais: reflexões para uma agenda de pesquisas sobre implementação de políticas públicas no Brasil. Revista de Administração Pública, v. 45, n. 6, p. 1943-1967, 2011. https://doi.org/10.1590/S003476122011000600015

ONU - Organizações das Nações Unidas. ONU e as mudanças climáticas. ONU Brasil, 2020. Disponível em: <https://nacoesunidas.org/acao/mudanca-climatica/>. Acesso em: 15 jun. 2020.

Pará. Lei no 9.048, de 29 de abril de 2020. Institui a Política Estadual sobre Mudanças Climáticas do Pará (PEMC/PA), e dá outras providências. Disponível em: <https://www.semas.pa.gov.br/wp-content/uploads/2020/05/Política-Estadual-SobreMudanças-Climáticas-do-Pará.pdf>. Acesso em: 5 jun. 2020.

Prata, R. Fórum de Mudanças Climáticas debate Programa REM e composição do Conselho Gestor. 2019. Disponível em: <http://www.mt.gov.br/-/11354216-forum-de-mudancasclimaticas-debate-programa-rem-e-composicao-do-conselho-gestor>. Acesso em: 19 jul. 2020.

Queiroz, B. L.; Barbieri, A. F; Confalonieri, U. E. Mudanças climáticas, dinâmica demográfica e saúde: desafios para o planejamento e as políticas públicas no Brasil. Revista Política e Planejamento Regional, v. 3, n. 1, p. 93-116, 2016.

Resende, F. M.; Denman, L. A. C.; Selva, G. V.; Campanhão, L. M. B.; Nobre, R. L. G.; Jimenez, Y. G.; Lima, E. M.; Niemeyer, J. A conceptual model to assess the impact of anthropogenic drivers on water-related ecosystem services in the Brazilian Cerrado. Biota Neotropica, v. 20, supl. 1, n. 1, e20190899, 2020. https://doi.org/10.1590/1676-0611-bn-2019-0899 
Rocha, W. M. "Da belle-epoque à bréa-epoque": relações internacionais e a governança das mudanças climáticas na Amazônia: um diálogo entre o público, o privado e o internacional no desenvolvimento sustentável dos Estados do Pará e do Amazonas. Brasília: Universidade de Brasília, 2019. (Tese de doutorado).

Rodrigues, P. C. O.; Pinheiro, S. L.; Junger, W.; Ignotti, E.; Hacon, S. S. Variabilidade climática e morbidade e mortalidade associadas a material particulado. Revista Saúde Pública, v. 51, 2017. https://doi.org/10.11606/s1518-8787.2017051006952

Silva, V. P.; França, G. L. S. Percepções de mudanças do clima, impactos e adaptação para sertanejos do semiárido. Revista Brasileira de Climatologia, v. 22, p. 229-248, 2018. https://doi.org/10.5380/abclima.v22i0.55958

Sousa, R. M.; Viola, M. R.; Chou, S. C.; Alves, M. V. G.; Avanzi, J. C. Projeções climáticas regionalizadas para o Estado do Tocantins, Brasil, nos cenários RCP 4.5 e RCP 8.5. Revista Brasileira de Climatologia, v. 24, p.330-347, 2019. https://doi.org/10.5380/ abclima.v24i0.57052

Suda, C. N. K.; Santini, M. F.; Rodrigues, E. Antártica e mudanças climáticas globais. Revista Técnica de Ciências Ambientais, v. 1, n. 1, p. 1-7, 2019. Disponível em: <http://www.agro.unitau.br/repositorio/index.php/rca/article/view/33>. Acesso em: 7 jun. 2020.

SUDAM - Superintendência de Desenvolvimento da Amazônia. Legislação da Amazônia. 2020. Disponível em: <http://www.sudam.gov.br/index.php/ouvidoria/58-acesso-ainformacao/86-legislacao-da-amazonia>. Acesso em: 22 jun. 2020.

Tocantins. Lei no 1.917, de 17 de janeiro de 2008. Institui a Política Estadual sobre Mudanças Climáticas, Conservação Ambiental e Desenvolvimento Sustentável de Tocantins, e adota outras providências. Disponível em: <https://www.normasbrasil.com.br/norma/lei-1917-2008-to_170684.html>. Acesso em: 5 jun. 2020.

Toledo, K. Atividades humanas já danificaram 75\% da superfície terrestre. Agência FAPESP, 2018. Disponível em: <http://agencia.fapesp.br/atividades-humanas-jadanificaram-75-da-superficie-terrestre/27430/>. Acesso em: 9 jun. 2020.

Wedy, G. Legislação brasileira sobre mudança climática precisa avançar. Revista Consultor Jurídico, 19 de janeiro de 2016. Disponível em: <https://www.conjur.com.br/2016-jan-19/gabriel-wedy-legislacao-mudanca-climaticaavancar>. Acesso em: 08 jun. 2020.

Informação da Licença: Este é um artigo Open Access distribuído sob os termos da Licença Creative Commons Attribution, que permite uso irrestrito, distribuição e reprodução em qualquer meio, desde que a obra original seja devidamente citada. 